\title{
Bullying in university between peers and by personnel: cultural variation in prevalence, forms, and gender differences in four countries
}

\author{
Maili Pörhölä ${ }^{1}$ (D) Kristen Cvancara ${ }^{2}$ (D) Esta Kaal ${ }^{3}$ (D) Kristina Kunttu ${ }^{4}$. \\ Kaja Tampere ${ }^{5}$ (D) Maria Beatriz Torres ${ }^{6}$ (D)
}

Received: 25 July 2018 / Accepted: 4 September 2019 / Published online: 15 October 2019

(c) The Author(s) 2019

\begin{abstract}
This study reports results from cross-cultural comparisons of (a) the frequency of university students' experiences of bullying victimization and perpetration between students, (b) students' experiences of bullying victimization by university personnel, and (c) the breakdown of victimization by the forms of bullying students have experienced. Gender breakdowns are offered. Survey data were collected from undergraduates in a total of 47 universities, using large sample sizes, similar measures and assessment methods in four countries: Argentina $(N=969)$, Estonia $(N=1053)$, Finland $(N=4403)$, and the United States $(N=2072)$. The results confirmed previous findings which suggest that a notable number of students experience bullying during university studies by fellow students and/or staff members, and a smaller number of students admit to bully their fellow students. The results add to previous knowledge by demonstrating remarkable cultural differences in the prevalence and forms of bullying and suggesting that bullying at the university level starts to transform similar to bullying in the workplace. The overall rates of bullying victimization and perpetration between students were the highest in Argentina, followed by the USA, Finland, and finally Estonia. However, victimization by university personnel was reported the most in Estonia, followed by Argentina, the USA, and Finland. Gender breakdowns in bullying experiences varied between countries. Verbal forms of bullying were common experiences. The most often reported form in all countries was unjustified criticism, belittling or humiliation related to academic performance. Students in the USA reported the highest frequencies in most forms of victimization. The results are discussed by reflecting on higher education features and comparing cultural characteristics of the countries. Practical implications are provided.
\end{abstract}

Keywords Bullying · Cross-cultural comparison · Higher education · University student $\cdot$ Victimization

Maili Pörhölä

maili.porhola@gmail.com

Extended author information available on the last page of the article 


\section{Introduction}

Although bullying has been widely recognized as a serious issue in elementary and secondary school (e.g., Craig et al. 2009; Currie et al. 2012; Nansel et al. 2001) and in the workplace (e.g., Keashly and Harvey 2005), and its long-term consequences on the psychosocial functioning, academic motivation and study ability of individuals have been found to reach from school year experiences even to higher education (e.g., Espelage et al. 2016; Holt et al. 2014; Pörhölä et al. 2019; Young-Jones et al. 2015), relatively little research has examined the prevalence and forms of bullying victimization and perpetration at the university level (Lund and Ross 2016). However, existing studies clearly indicate that bullying does occur among higher education students, and occurrence rates vary substantially between individual studies (Cowie et al. 2013; Lund and Ross 2016; Marraccini et al. 2015). Although the level of cyberbullying seems to be increasing among university students, traditional forms (i.e., verbal, relational, physical) of peer bullying are still more commonly reported (Cowie et al. 2013; Lund and Ross 2016; Matsunaga 2010; Wensley and Campbell 2012).

Students do not experience bullying victimization only by their fellow students but also by university personnel (Chapell et al. 2004; Marraccini et al. 2015; NUS 2008; Sinkkonen et al. 2014). This kind of bullying, however, has received very little attention so far. Yet, it may cause students even more stress and harm, as staff members are in a more stable position at the university and are expected to have power over students' academic success. As Keashly and Wajngurt (2016) note, faculty occupy a central position in the creation of the university learning environment as the architects of research and curriculum design and delivery, and therefore influence student engagement and learning. Being bullied by a person in such an influential position could be devastating for students' motivation and ability to study.

A review of the small body of research on bullying at university indicates three main limitations exist. First, comparisons of existing studies suggest great variation in the occurrence of bullying in universities between different countries; with only a small number of cross-cultural comparison studies conducted, and a maximum of only two countries involved per study (Lund and Ross 2016). Second, a clear majority of existing studies have used relatively small sample sizes and/or single university samples, based mostly on convenience sampling techniques. Third, psychometric measures have varied between studies, which complicates comparisons and decreases validity in comparative analyses. Based on their literature review demonstrating these shortcomings, Lund and Ross (2016) concluded that researchers should conduct studies using cross-university national or international samples in order to better capture the prevalence of bullying among university students. Thus, by collecting data from multiple universities via consistent sampling and measures, researchers could control for methodological and measurement variance and thus better assess if and how bullying involvement differs according to institutional and student characteristics.

Hence, in the current study data were gathered from multiple universities in four countries, involving large sample sizes and similar measures to compare experiences of bullying victimization and perpetration among university students. In addition, the study provides data on the prevalence of students' experiences of 
being bullied by personnel at university, as well as on the forms of bullying that students experience during their higher education. Gender breakdowns for each analysis are included.

The four countries examined (Argentina, Estonia, Finland, and the United States) represent different cultures on three continents. These countries were chosen because they differ from each other not only by their geographical location and size, but also by some cultural, historical, and developmental characteristics, which may have an impact on university students' experiences of bullying. On the one hand, compared with Estonia and Finland as small countries representing relatively homogenous cultures, the wider cultural diversity (ethnic, political, religious) in Argentina and the USA can be anticipated to generate more bullying between university students in these countries. On the other hand, while Finland and the USA have a quite stable recent history in political and economic development in society, the instability in societal development in the recent history of Argentina and Estonia is obvious and may still be reflected in the development of academic cultures with higher social status differentials and higher levels of authoritarianism. This in turn may influence students' experiences of bullying by their teachers and staff.

A further factor that affected selection of the four countries was the status of human development and equality within each country. The Human Development Reports Human development indices and indicators 2018 provided by the United Nations (see, Human development indices and indicators 2018) compare nations by means of a Human Development Index (HDI), which is a composite index focusing on three basic dimensions of human development: the ability to lead a long and healthy life (measured by life expectancy at birth); the ability to acquire knowledge (measured by mean years of schooling and expected years of schooling); and the ability to achieve a decent standard of living (measured by gross national income per capita). The four countries chosen for this study differ by this index. Comparisons of the HDI values between 189 countries in 2017 rank the USA on 13th and Finland 15th of the top, Estonia 30th, and Argentina 47th; yet all these countries represent the category of "very high human development" with 58 countries included. However, the values of the coefficient of human inequality, which indicates the average inequality in the three basic dimensions of human development, showed that, of the four countries, highest in inequality were Argentina $(13,9)$ and the USA $(13,1)$, whereas Estonia $(8,5)$ and Finland $(5,5)$ represented countries of better equality. These cultural characteristics add to the possible consequences of higher diversity between individual students in Argentina and the USA, though simultaneously suggest some benefits (better health and economy, more education) of having higher levels of human development in the USA and Finland.

If these potential elements are embedded in university culture, they may affect bullying phenomena across the four countries so that bullying by other students and by university personnel would be least frequently experienced by students in Finland and most frequently by students in Argentina. While moderate levels of bullying among students could be expected in Estonia and the USA, the higher status hierarchy between students and teachers might increase students' experiences of being bullied by personnel in Estonia. 


\subsection{Experiences of bullying between fellow students}

Relatively little is known about peer bullying in postsecondary education. Lund and Ross (2016) conducted a comprehensive search of the existing peer-reviewed literature and only found 14 studies that reported the prevalence of bullying perpetration, victimization, or both, among college or university students; all of them being published between 2004 and 2014. Ten of these studies were conducted exclusively in the USA and two studies in other countries: Australia (Wensley and Campbell 2012) and Finland (Sinkkonen et al. 2014). Two additional studies were conducted using samples from both the USA and another country (Canada and Japan). Hence, according to Lund and Ross (2016), no previous study reporting the occurrence of bullying among college or university students has included more than a maximum of two countries and two continents. While sample sizes ranged from 119 to 2085 participants, most studies drew participants from either convenience samples or artificial subsamples, such as students in a particular class or set of classes. Only three studies used multi-university samples, which included one university in the USA and one in Japan (Matsunaga 2010), two universities in Canada and one in the USA (Beran et al. 2012), and eight universities in the USA (Rospenda et al. 2013).

Substantial variations between studies in the occurrence of both bullying victimization and perpetration exist at the postsecondary level of education (Lund and Ross 2016). Overall prevalence for the eight studies reporting traditional (non-cyber) bullying victimization ranged from 5 to $70 \%$, with an average about 20-25\%; and of the seven studies assessing cyberbullying victimization, prevalence ranged from 8.6 to $43.3 \%$, with an average of $10-15 \%$. For the four studies reporting traditional bullying perpetration, prevalence ranged from 5.1 to $21.8 \%$, with an average of $20 \%$; and for the three studies reporting cyberbullying perpetration, the overall prevalence ranged from 3.8 to $9.9 \%$, with about $5 \%$ on average (including $2.4 \%$ who were perpetrator-victims). While the wide range in results between studies can partly be explained by differences in the measures used and in the ways of reporting bullying experiences, cultural variation may also play a role.

Research investigating cultural variations between occurrence rates of bullying in postsecondary education is warranted because although a majority of the studies reviewed by Lund and Ross (2016) were conducted in the USA, research is being conducted within other countries as well. While there are no studies to report occurrence rates of bullying at universities in Argentina or Estonia, these rates have been examined in Finland and the United Kingdom. The University Student Health Surveys investigate every 4 years students' well-being and health-related behavior in Finland. Using representative random samples of undergraduate Finnish students from all universities, these surveys have indicated that, during their higher education, from 5 to $7.5 \%$ of students have been bullied at least occasionally by their fellow students, while approximately $2 \%$ admit they have bullied other students (Kunttu and Pesonen 2013; Kunttu et al. 2017; Pörhölä 2017). In another study conducted in one university in Finland, Sinkkonen et al. (2014) found that, of the 2805 respondents, a total of $5 \%$ reported they had been bullied at university, but only in half of the cases, another student was identified as the bully. 
In comparison, the National Union of Students' (NUS) Student Experience Report (NUS 2008) provides an overview of students' experiences at university across the United Kingdom. Data from a total of 3135 students from 146 higher education institutions, revealed that $7 \%$ of the students had experienced bullying during their time at university, with $79 \%$ of them indicating that the bullying was carried out by another student. Nursing and medical students seem to be particularly at risk of experiencing bullying during their education (e.g., Ahmer et al. 2008; British Medical Association [BMA] 2006; Curtis et al. 2007).

Gender may also impact bullying experiences at university across different cultures. While studies reveal bullying victimization within the USA is reported at similar rates by males and females, males were noted to report a higher rate of bullying perpetration among university students (Lund and Ross 2016). In Greece, Giovazolias and Malikiosi-Loizos (2016) found more males were engaged in bullying and cyberbullying, both as perpetrators and victims, than were females in their sample of 464 university students. Due to these differences, biological sex was also measured in the current study.

\subsection{Experiences of bullying by university personnel}

In addition to occurrence rates of bullying among students, university personnel (including teaching, research, and administrative personnel) hold roles of authority and power within the higher education setting. In academe, teaching/research personnel are a key influence in the culture and climate of the institution (Keashly and Wajngurt 2016), therefore shaping the social context in which students work with them and with their peers. It is expected that all university personnel follow appropriate and acceptable communication behavior, no matter which role they hold. Hence, if students perceive that university personnel bully one or several students, they might adopt similar behaviors and regard them as acceptable behavioral choices in the academic context. Therefore, it is important to examine bullying that is communicated by university personnel to students.

Occurrence rates of students' experiences of being bullied by university personnel are not commonly reported, however, studies from the USA, Finland, and the United Kingdom indicate this kind of bullying exists (Chapell et al. 2004; Cooper et al. 2011; Lavikainen 2010; Marraccini et al. 2015; NUS 2008; Sinkkonen et al. 2014). In the study by Chapell et al. (2004) among 1025 undergraduate students in a U.S. university, the number of students who reported having been bullied by a college teacher occasionally was $4.2 \%$, and very frequently by only $0.5 \%$ of the students. Quite similarly, Marraccini et al. (2015) found that of the 337 students recruited from a U.S. college, $3.1 \%$ reported having been bullied by a teacher/researcher occasionally and $0.9 \%$ very frequently. In a study conducted among 5698 higher education students in Finland, students also reported less bullying from teaching/research personnel than from their fellow students (Lavikainen 2010). In the United Kingdom, it was found that of the $7 \%$ of students who reported having experienced bullying during their time at university, $24 \%$ said it was carried out by university personnel, while the rest of them identified another student(s) as their bully (NUS 2008). 
While these studies suggest that bullying in colleges and universities is more often carried out by peers than personnel, conflicting findings also exist. The study by Sinkkonen et al. (2014) in one university in Finland revealed that bullying victimization was experienced as often by university personnel as it was experienced by peers. In $44 \%$ of the cases the bully was a teacher/researcher and in $6 \%$ of the cases an administrator. Gender differences in students' experiences of bullying by personnel were not found in these studies.

To sum up, remarkable differences in university students' experiences of bullying by peers as well as by personnel exist between studies. While this variation might result from different methodological choices made in these studies, it could also suggest the existence of cross-cultural differences, which could be more reliably detected if similar methods were used between studies. Hence, by using similar methods in four countries and including gender breakdown analyses, this study is the first of its kind to report cross-cultural comparisons in response to the following two research questions: (RQ 1) "What is the frequency of university students' experiences of bullying victimization and perpetration between fellow students?" and (RQ 2) "What is the frequency of students' experiences of bullying victimization by university personnel?"

\subsection{Forms of bullying at university}

\subsubsection{Operationalizing bullying across cultures}

Operationalizations used to measure different forms of bullying in the university context have varied across studies. While some studies have focused only on cyberbullying and its forms (e.g., Finn 2004; Kraft and Wang 2010; Schenk and Fremouw 2012) or traditional forms of bullying (e.g., Chapell et al. 2004, 2006; Cooper et al. 2011; Marraccini et al. 2015; Pontzer 2010; Sinkkonen et al. 2014), others have included both traditional and cyber bullying (e.g., Beran et al. 2012; Giovazolias and Malikiosi-Loizos 2016; Matsunaga 2010; Rospenda et al. 2013; Wensley and Campbell 2012; Young-Jones et al. 2015). When multiple forms of bullying have been operationalized in studies, respondents have typically been provided first a definition of bullying, followed by a set of categories of bullying behaviors and asked about their personal experiences with each.

While the provision of a definition of bullying is a reasonable strategy to ensure study validity, differences remain in the ways bullying has been operationalized depending on whether the study was developed from school versus workplace contexts. In most studies, categories of bullying behavior have been adopted from literature on school bullying and they have included some or all of the following: (a) verbal aggression, for example, saying hurtful things, ridicule, calling hurtful names; (b) relational/social damage, such as ignoring or socially excluding the person, or making other people dislike the person by, for example, spreading nasty rumors or telling lies about him or her; (c) physical aggression, such as physical attack, threat, or property damage; and (d) cyberbullying, consisting of different forms of hurting by means of communication technology (e.g., Beran et al. 2012; Chapell et al. 2006; 
Matsunaga 2010; Rospenda et al. 2013; Sinkkonen et al. 2014; Young-Jones et al. 2015). In comparison, in their study of college students' experiences of bullying by peers and teaching/research personnel, Marraccini et al. (2015) developed a questionnaire based on previously used measures designed to assess exposure to workplace bullying. In addition to items assessing personal or relational, and physically intimidating forms of bullying, they included measures of academic bullying such as humiliation or ridicule in connection with studies, insulting or offensive remarks, hints of being incompetent, having comments ignored, and withholding of information. Also Rospenda et al. (2013) used a modified version of a workplace harassment scale, and included items assessing forms of bullying which could be characteristic in university context (e.g., being excluded from important meetings or events; being yelled at or talked down to; being manipulated; feeling pressured to do something against one's own will; and having requests for help ignored). Unfortunately, neither of these two studies reported the breakdown by different forms of bullying.

\subsubsection{Occurrence of bullying forms across cultures}

In addition to the variation in the definition of bullying, inconsistency in the reporting of results complicates comparisons between individual studies. Some studies (Pontzer 2010; Sinkkonen et al. 2014) have reported the breakdown of victimization by multiple types of bullying (verbal, relational, physical, cyber), some studies have reported more generally on traditional and cyberbullying (Beran et al. 2012; Giovazolias and Malikiosi-Loizos 2016; Wensley and Campbell 2012); while other studies report only overall victimization rates.

Although existing studies have more recently focused heavily on cyberbullying, results from studies in different countries indicate the occurrences of non-cyberbullying, especially verbal and relational forms, are considerably higher than those of cyberbullying. For example, in the study by Wensley and Campbell (2012) among 528 first year university students in Australia, 21\% of respondents reported being a victim of traditional bullying in the preceding 12 months, while $12 \%$ reported being victims of cyberbullying; $5 \%$ had been perpetrators of traditional bullying and $4 \%$ perpetrators of cyberbullying. In Greece, Giovazolias and Malikiosi-Loizos (2016) found $6.3 \%$ of their respondents had been a victim of traditional bullying, while $3.2 \%$ reported having been a victim of cyberbullying, in the preceding 12 months; $1.7 \%$ had bullied a fellow student in traditional forms, and $1.3 \%$ reported perpetration of cyberbullying.

When specific forms of bullying are operationalized, studies indicate a variance in the occurrence of bullying experiences across cultures. For example, in the study by Chapell et al. (2006) among 119 undergraduates in the USA, those who were bullied in college by fellow students, teachers, or coaches, reported more verbal bullying than social (relational) bullying experiences, while physical bullying was least commonly reported. In contrast, the study in Greece (Giovazolias and Malikiosi-Loizos 2016), revealed relational bullying (social exclusion) was the most common form of bullying, followed by verbal bullying. Similar findings were detected in Finland, where social exclusion from student groups was the most typical form of peer bullying (Lavikainen 2010). Furthermore, using a sample of 292 Japanese and 296 U.S. 
undergraduates, Matsunaga (2010) found that the most often reported form of bullying by fellow students was relational bullying, followed by online/cyber bullying, physical bullying, and finally property/material related bullying. In this study, however, forms of verbal bullying were included in the category of relational bullying.

Finally, the small number of studies which have included assessment of academic/study-related bullying have shown that this type of bullying is experienced by university students from both peers and personnel (Cooper et al. 2011; Sinkkonen et al. 2014). Cooper et al. (2011) found among 636 senior year students in nursing schools in the USA, that, while students were identified as main perpetrators of relational bullying, teaching/research personnel were the most frequently reported source of study-related forms of bullying. Actual or threats of physical aggression were rarely reported.

\subsubsection{Gender differences across cultures}

Gender differences in forms of bullying experiences have been found in the USA, but have not been verified in other countries. For example, Pontzer's study (2010), which included 527 U.S. university students, found a higher percentage of males compared to females were victims of verbal, physical, and racial bullying (i.e., mean comments about one's race), and property damage (i.e., having money or belongings stolen or damaged), while females experienced a higher percentage of relational and sexual bullying (i.e., mean names or comments with a sexual meaning). More males compared to females engaged in every type of bullying perpetrated. According to Lund and Ross (2016), there is no clear evidence of gender differentiation in cyberbullying victimization among college students.

Hence, including gender breakdowns, this study examines cross-cultural variation in response to the third research question: (RQ 3) "What is the breakdown of victimization by the forms of bullying students have experienced during their university education?"

\section{Methods}

\subsection{Data collection and participants}

In the four countries, data were collected in 2012 and 2013 from undergraduates on several fields of study. In each country, data were collected from more than one university. It was possible to collect representative samples of the whole university student population in Estonia and Finland. However, in Argentina and the USA, where student populations are large, this was not possible with reasonable effort and resources, and therefore, two universities were chosen for data collection in each of those countries. Data collection, participant description, and ethical review procedures are summarized in Table 1.

Participants were generally representative of the campus populations in each country, with a few exceptions. In Estonia, participants $(\mathrm{N}=1053)$ were 
representative of the student population by age group and study fields, but not by universities: two universities were overrepresented and one underrepresented. Also male students were underrepresented. In Finland, participants $(\mathrm{N}=4403)$ were representative of the study population with respect to age, university, educational sector (academic vs. applied), and field of study; males were slightly underrepresented. In Argentina, the participants $(\mathrm{N}=969)$ were not representative of all fields of study, with social sciences somewhat overrepresented and human sciences underrepresented; gender and age groups corresponded well with the distributions of students in the public, but not the private, university. In the United States, participants $(\mathrm{N}=2072)$ represented the age groups, but males were underrepresented. Not all fields of study were consistently represented across the universities, however, of the fields that were consistent, the ratio of respondents was similar to those of the campuses.

\subsection{Completion of the survey}

The survey questionnaire was modeled after the Finnish University Student Health Survey (Kunttu and Pesonen 2013) which utilized a variety of scales to measure physical, mental and social health, health behavior, study ability, as well as experiences of bullying, stalking, and violence. At the beginning of the questionnaire, participants were asked to provide demographic information, including age, gender, location of the university attended, field of studies, and level of study. After this, the number of measures included in the questionnaire varied between countries according to the specific needs of the researchers in each country. The present analysis only focuses on students' report of bullying experiences during university studies.

The questionnaire was available for the participants in Spanish in Argentina, Estonian and Russian in Estonia, Finnish and Swedish in Finland, and English in the USA. In all instances where data were collected, either using paper and pencil method or web-administered questionnaires, the purpose of the study as well as the responsible researchers and institutions were first introduced. Students were told how long completing the survey would take and reminded that participation was voluntary and anonymous. Participants gave their informed consent by returning a completed survey questionnaire. In case students experienced painful memories due to responding to the survey and wanted to discuss them with someone, they were encouraged to seek professional support from student health services or their own primary care doctors. The survey was not connected in any way to the course work of students and no extra credit was offered if they decided to participate in it. As incentive to increase participations, students in Argentina, Finland, and the USA were offered the opportunity to enter a raffle for several items (e.g., iPod, USB drives, wireless mouse) upon completion of the survey. 


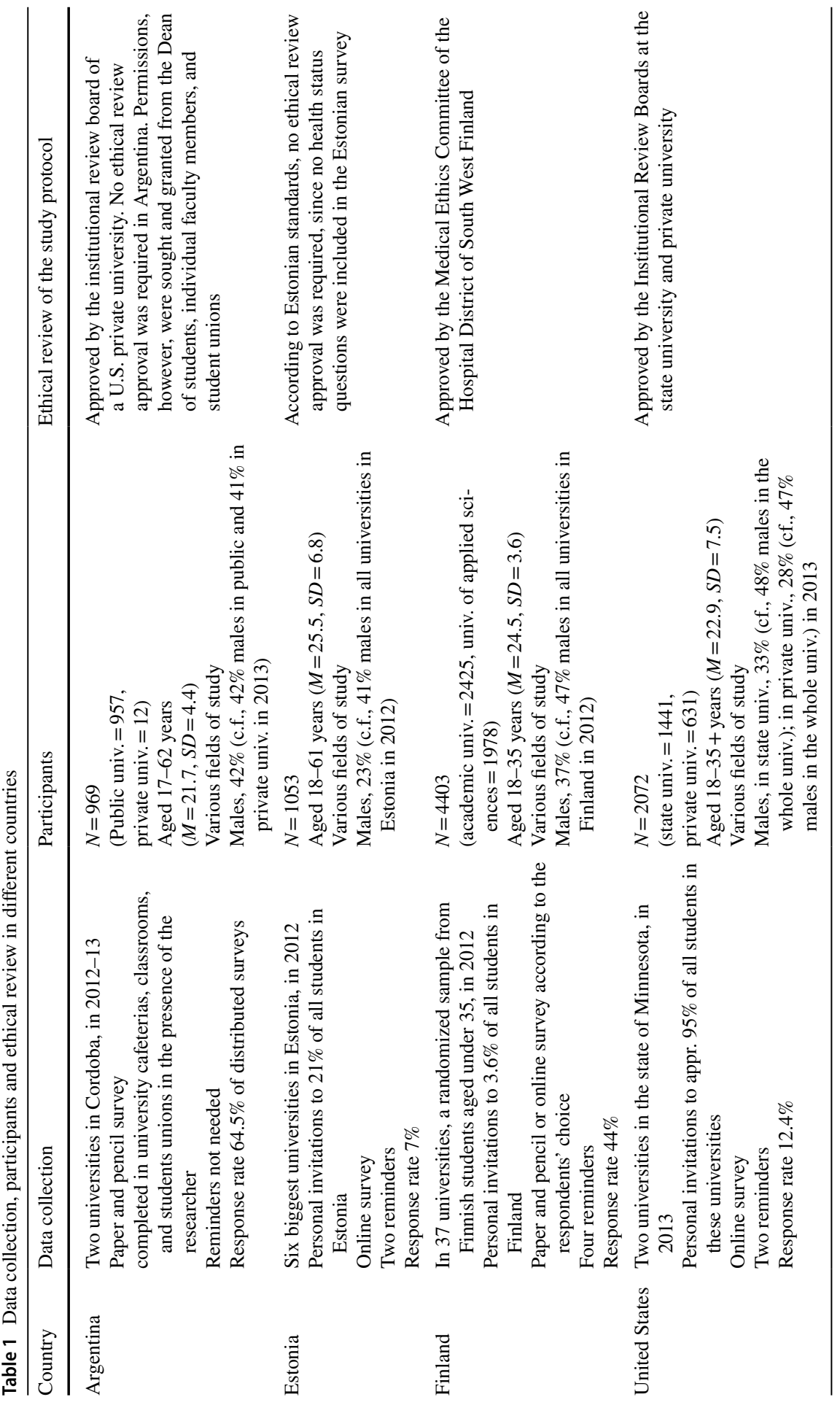




\subsection{Assessment of bullying victimization and perpetration}

The definitions previously provided of bullying arise from either school or workplace contexts, and stress three components of the phenomenon: (a) the target person is exposed to aggressive behaviors or intentional/goal-directed doing of harm by the perpetrator(s); (b) this harm-doing is carried out repeatedly; (c) the target person is somewhat helpless against the perpetrator(s) due to the existing power imbalance between them (e.g., Olweus 1993; Volk et al. 2014). These components have been found to be widely adopted as criteria for bullying (Gladden, Vivolo-Kantor, Hamburger, and Lumpkin 2014; Volk et al. 2014). In the present study, these criteria were adopted in the definition of bullying provided to the respondents, however, they were verbally adjusted into the social context of higher education. For example, three main categories of bullying (verbal, physical, and relational) were represented to help respondents identify bullying behaviors. Further, as the study primarily focused on victims' perspective and experiences of bullying, the intentions and goals of the perpetrator would not have been possible to know and were ignored in the definition given in this study. Hence, we chose to use a definition developed by Pörhölä for the Finnish University Student Health Survey (see, Kunttu and Pesonen 2013). Before completing the survey section regarding experiences of bullying, respondents were provided the following definition: "Bullying refers to a situation in which an individual is the object of recurring insult, damage, and/or discrimination by one or several persons without being able to influence how she/he is being treated." Then students completed information about their bullying experiences.

Regarding bullying occurrence rates at university, students were asked to report (RQ1) the frequency of victimization by other students and the frequency of bullying other students, as well as (RQ2) the frequency of victimization by university personnel. All three items were measured on a scale ranging from 0 to 2: $0=$ never, $1=$ occasionally, and $2=$ often .

Regarding forms of bullying, students were also asked to report on (RQ3) specific bullying behaviors they had experienced at the university. As the present study focuses on young adult students' experiences in university context, who are in a transition phase from school to working life, it was deemed important to include assessment of study-related academic forms of bullying, in addition to verbal, relational, physical, and technologically-mediated (cyber) forms. Hence, the following categories of bullying forms were assessed: (a) verbal attack (e.g., abuse, name-calling, threat); (b) physical damage to you or your belongings; (c) unjustified criticism, belittling or humiliation related to your studies; (d) mocking or criticism related to your personal qualities (e.g., appearance, age, gender, religion, background); (e) damage to your peer relationships or social discrimination; and (f) technologically-mediated insulting or harassment (e.g., via the Internet or phone). The frequency of these experiences was measured on a scale: $0=$ never, $1=$ occasionally, and $2=$ often.

As there is no consensus among researchers on how bullying in university context should be defined and assessed, definitions and measures have greatly varied between studies. Because different methodological choices may result in different findings, in cross-cultural research such as the current study, it was deemed important to use similar definitions, measures, and collection techniques in all data collection in the four countries compared. 


\subsection{Data analysis}

Data were analyzed using STATA 13.1 for the Argentina data and IBM SPSS Statistics software for other data. Descriptive statistics (frequencies and frequency percentages) were used to indicate cultural similarities and differences in students' experiences of bullying. Due to the skewed distribution of variables assessing bullying experiences, nonparametric Mann-Whitney $U$ tests were run to indicate possible gender differences.

\section{Results}

\subsection{Bullying between students: RQ1}

When students were asked about the frequency of having been victimized by their fellow students, their responses varied notably between the four countries compared (see Table 2). Highest rates of bullying victimization were reported in Argentina, where $25.2 \%$ of all respondents indicated that they had been bullied by other student(s) at least occasionally. This was followed by the USA (11.9\%), and Finland $(5.3 \%)$, with lowest rates $(2 \%)$ being reported in Estonia. Highest rates of bullying other students at least occasionally were reported also in Argentina (5.5\%), followed by the USA (3.5\%), Finland (2.3\%), and finally Estonia (1.7\%; see Table 3). In each country, victimization was reported more often than bullying perpetration.

Gender differences in bullying roles also varied between the countries. While statistically significant gender differences in victimization by fellow students were detected only in Finland where female students reported having been bullied more often than male students, in other countries, gender differences were nonsignificant (see Table 2). However, in Argentina, Estonia, and the USA, male students reported bullying perpetration of their fellow students more than female students did. In Finland, gender differences in bullying perpetration were nonsignificant (see Table 3).

\subsection{Bullying by university personnel: RQ2}

When students were asked about their experiences of having been bullied by university personnel, cultural variation appeared differently, as compared with peer bullying experiences (see Table 4). Having been bullied by university personnel at least occasionally was reported most often by students in Estonia (16.2\%), followed by Argentina (9.5\%) and the USA (8.9\%), and least often in Finland (6.5\%). Although female students reported victimization by university personnel more often than male students in all other countries except for Argentina, gender differences reached a statistically significant level $(p<.05)$ only in Finland. 


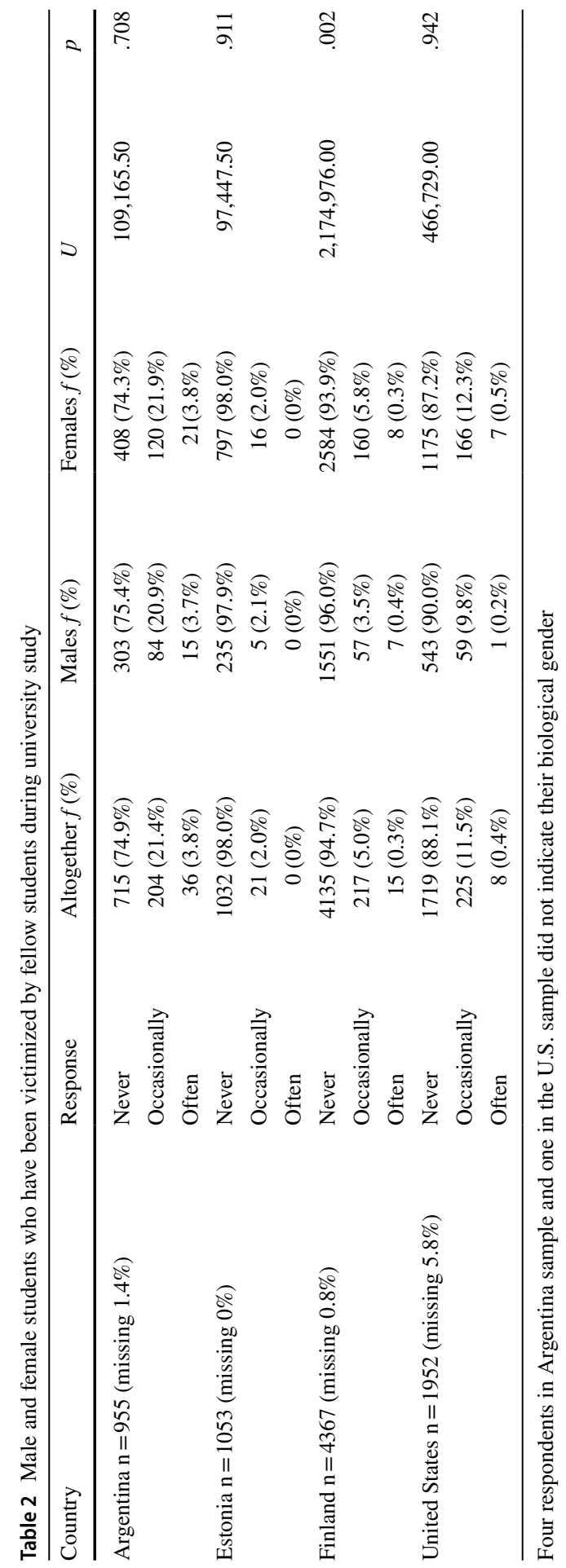




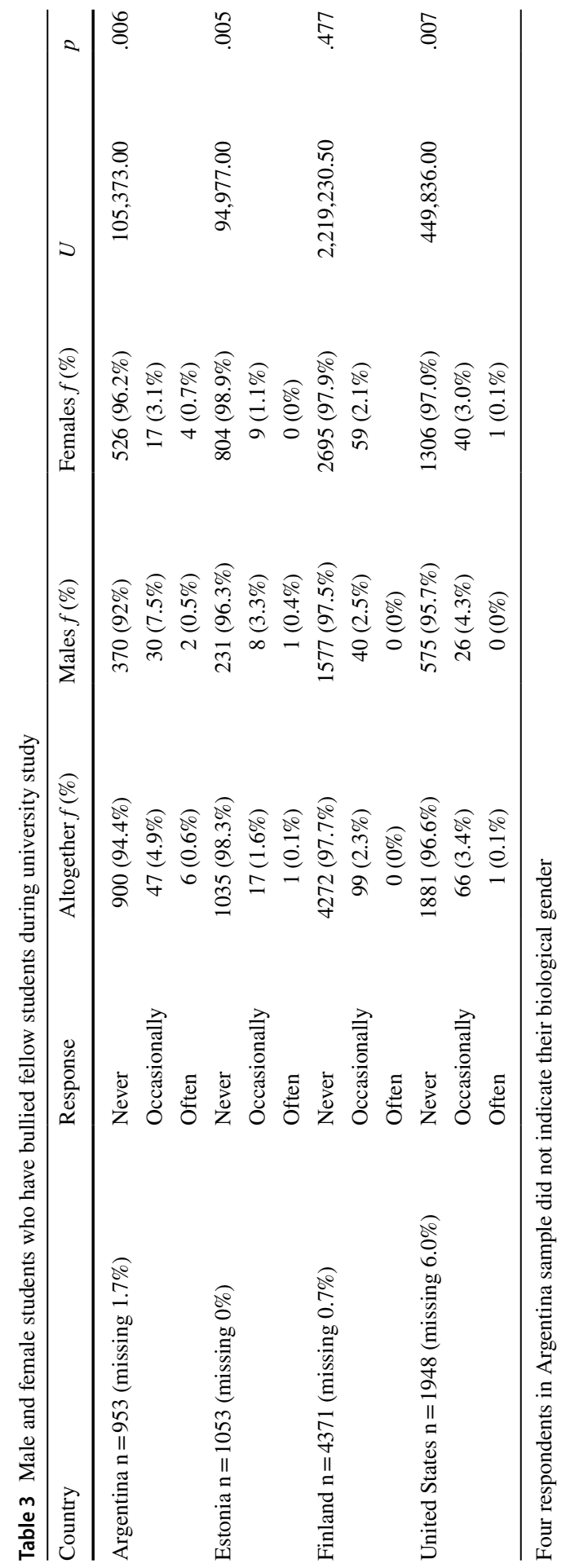




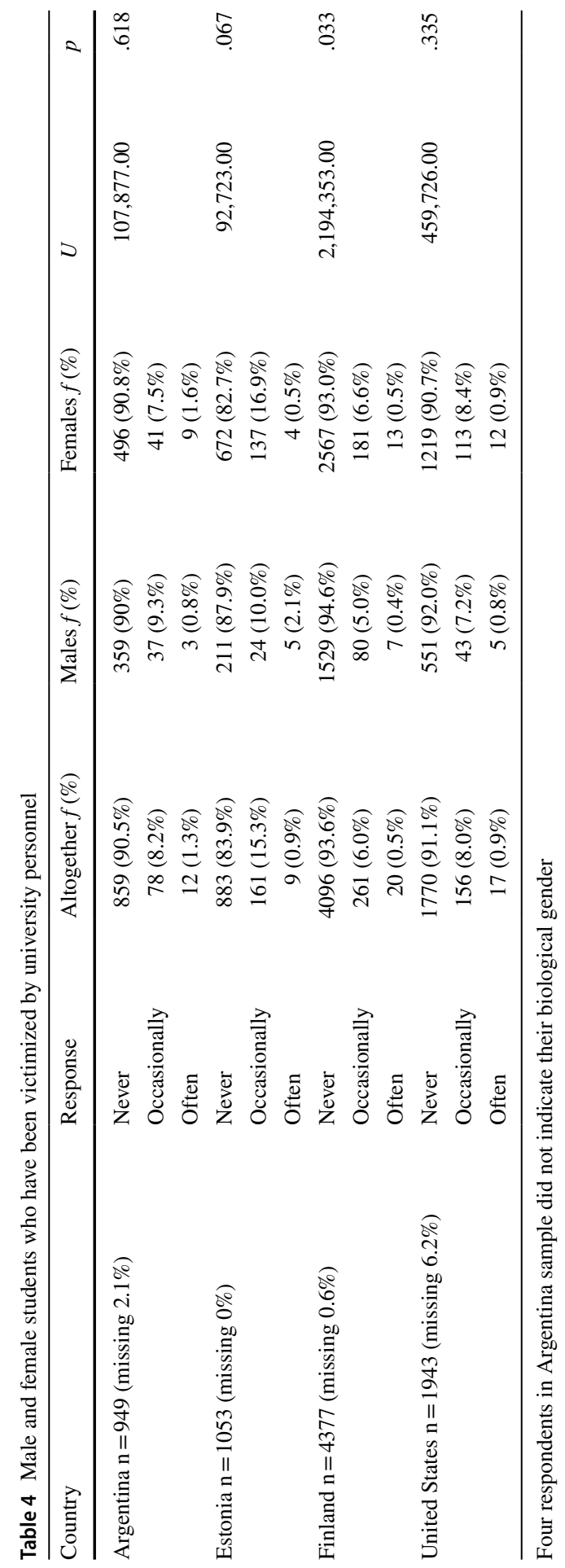




\subsection{Forms of bullying experienced by students: RQ3}

When students were provided with a list of different forms of bullying and asked to indicate how frequently they had been subjected to each form of bullying at university, only a small number of respondents (max. $2.2 \%$ ) reported having been the recipient of any of the listed forms of bullying often, and therefore the categories "often" and "occasionally" were combined for analysis (see Table 5). The highest frequencies were reported by students in the USA in most forms of bullying (i.e., verbal attacks, mocking or criticism related to personal qualities, damage to peer relationships or social discrimination, physical damage to the person or his or her belongings). However, unjustified criticism related to studies was reported most frequently by Estonian students, and technologically mediated insulting or harassment by students in Argentina. The lowest rates of most forms of bullying were reported in Estonia and Finland.

Across the countries' samples, the most often reported form of bullying victimization was unjustified criticism, belittling, or humiliation related to studies. This type of bullying was reported by female students most often (varying from 13.3 to $15.1 \%$, between countries), and also by male students in Finland (9.2\%) and Estonia (10.9\%). In Argentina, the most often reported form of bullying by male students was verbal attacks (15.4\%), and in the USA, it was mocking or criticism related to personal qualities $(11.8 \%)$.

Overall, the most often reported forms of bullying were verbal by nature. Experiences of verbal attacks and mocking or criticism related to personal qualities were experienced to almost the same extent in all other countries except for Estonia. Damage to peer relationships or social discrimination was reported more often by female than male students in all other countries except for Argentina. The experiences of technologically mediated insulting or harassment varied from approximately $1 \%$ in Estonia and Finland to $4.2 \%$ in the USA and $4.9 \%$ in Argentina. The least often reported form of bullying was physical damage to the person or their belongings, the number of male students who reported these experiences varying from $0.8 \%$ in Estonia to $3.1 \%$ in Argentina, and female students from $0 \%$ in Estonia to $2.4 \%$ in the USA.

\section{Discussion}

The results of the survey conducted with similar measures in four countries confirmed previous findings which have shown that students do experience bullying during their university studies, by both their peers (Lund and Ross 2016; Pörhölä 2017; Sinkkonen et al. 2014) and university personnel (Chapell et al. 2004; Marraccini et al. 2015; NUS 2008; Sinkkonen et al. 2014). Although a portion of students admit to bullying their fellow students (Lund and Ross 2016; Pörhölä 2017), the number of bullies was notably smaller than the number of students who identified themselves as victims. The differences in occurrence rates and forms of bullying reported are discussed in relation to a variety of cultural features, including prominence of hierarchy norms, homogeneity of the people, gender, contextual norms regarding the communication of feedback, and the non-mandatory nature of higher education. 


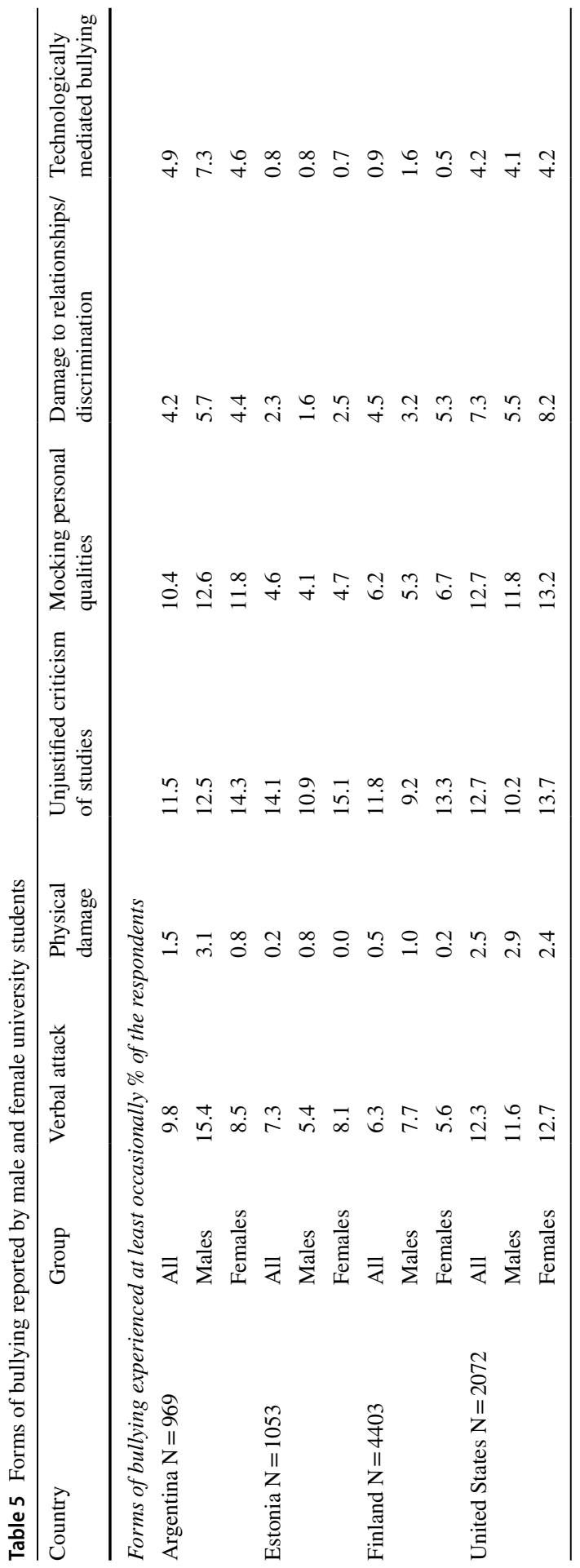


Differences in occurrence rates and forms of bullying were found to exist across the four countries in the study. While the overall rates of bullying victimization and perpetration among students were the highest in Argentina, followed by the USA, Finland, and finally Estonia, this order interestingly changed when being bullied by university personnel was examined. The highest numbers of victimization by university personnel were reported in Estonia, followed by Argentina, the USA, and finally Finland. When the students were asked more specifically about having been exposed to different forms of bullying, students in the USA reported the highest frequency in most bullying forms.

Several cultural features can explain differences found among countries, some of which are briefly discussed here. To begin with, the large cultural and socio-economic diversity that exists in student populations in Argentina and the USA might create tensions between individual and groups of students, resulting in higher rates of bullying which were detected among students in these countries. A further explanation for the high rates of bullying in Argentina could be that the country has experienced various political conflicts, military dictatorships, and several economic crises, which may have resulted in social fragmentation, suspicion of authorities, and increase of certain forms of violence even in higher education (see, Noel et al. 2009). In addition, at the time of the research the university where data were collected did not have a bullying policy, indicating it to be less commonly identified as a social phenomenon.

Hierarchy is a dimension of culture that embodies notions of power and subordination. Due to their political history, both Argentina and Estonia still tend to be more hierarchical societies, where power is demonstrated, for example, through titles and positions. Also, teaching traditions can be quite authoritarian and teacher centered. These might partly explain the high frequencies of bullying victimization by university personnel in these countries. While students in Estonia reported the highest of all frequencies of victimization by personnel, they also reported lowest frequencies of victimization by peers. One explanation for this could be found in international comparisons which indicate the rates of peer bullying among Estonian school children are among the highest (Currie et al. 2012). It is possible that, through their earlier experiences of peer bullying, students are socialized to regard bullying among peers as 'normal' behavior to be expected. Combined with that, in Estonia, individuals' ability to defend themselves in peer relationships seems to be highly valued, possibly resulting in university students tending to avoid reporting on their experiences of peer victimization. Regarding university personnel, after Estonia became fully independent in 1991 from the occupation by the Soviet Union, social expectations of the development in the country focused on a less hierarchical approach. As a result, university students might have expectations of higher equality with their teachers and could therefore be more sensitive to report on bullying they experience from teachers than from peers.

The costs of higher education can provide a further explanation to the cross-cultural differences in bullying experiences. While Argentina and Finland, and nowadays also Estonia, offer free attendance to public universities, students or their families must pay for higher education in the USA, and by the time of data collection also in Estonia. The high financial costs of getting a higher education degree can 
cause stress and increase competition among students because there is greater diversity in student preparation to be successful at university, more pressure to do well, to make the right field of study choice, and to get out of university as efficiently as possible. In university cultures with higher status differentials between students and teachers and teaching traditions being more teacher centered, like in Estonia, the fact that students need to pay for their education may raise their expectations of being treated more respectfully by university personnel. This could be reflected in students' perceptions of receiving negative study-related criticism from their teachers, which might be experienced as being bullied by them. The highest frequencies of unjustified criticism related to studies that were reported by Estonian students may therefore reflect their communication experiences with teachers rather than peers.

In the USA, representing a less authoritarian culture with relatively low status hierarchy between students and teachers, the heavy financial costs of university studies can rather be reflected in increased competition between students, and lead to experiences of being bullied by fellow students rather than by university personnel. A study by the Organisation for Economic Co-operation and Development (OECD) looking at higher education costs throughout the world found that the USA has the highest average tuition costs of the 35 OECD member countries (including Estonia and Finland, but not Argentina), for both public and private institutions at the bachelor's level (Education at a glance 2017). The large socio-economic diversity in the U.S. student population can cause further tensions between students.

The homogeneity of each culture may also be a useful dimension to examine the difference in rates and forms of bullying experienced at university. The relatively low frequencies of bullying that were reported in Finland among students and by personnel can be understood by considering Finnish cultural homogeneity. Similarly with Estonia, the Finnish student population is quite homogenous culturally, socioeconomically, and educationally, and even political and religious diversity is relatively small, which may reduce possible conflicts between students. Such levels of homogeneity are not as prevalent in Argentina and the U.S. university student populations. Further, in the Finnish education system with equal free access offered to university studies to all and similar financial aid provided by the state for living expenses, students do not need to compete with each other to maintain their student status or to earn an academic degree. These features might decrease students' stress level and promote the development of better relationships with peers and personnel.

Regarding gender differences, the results suggest a continuity in the aggressive behavior of males, compared to that reported of females. Male students dominated as bullying perpetrators in each country, except for Finland, which is consistent with findings from elementary and middle school levels (e.g., Craig et al. 2009; Currie et al. 2012; Nansel et al. 2001; Seals and Young 2003) as well as at university (Chapell et al. 2004; Giovazolias and Malikiosi-Loizos 2016; Lund and Ross 2016). Inconsistent with findings from elementary and middle schools where male students are also more often victimized than female students, gender differences in victimization were nonsignificant, except for Finland, suggesting that in young adulthood males would become less vulnerable to bullying. Previous studies at the university level have reported conflicting results regarding gender differences in bullying victimization (cf., Chapell et al. 2004; 
Giovazolias and Malikiosi-Loizos 2016; NUS 2008; Lund and Ross 2016), suggesting that cultural features might have an impact on these differences. Compared with other countries in this study, divergent findings were found in Finland to demonstrate higher rates of victimization by peers and personnel for female students and no gender differences in bullying perpetration. The finding suggests that female students in Finnish universities are bullied by other females more than they are in three other countries. It could also be interpreted to reflect lower levels of 'masculine power' in Finnish universities. Overall, gender trends were recognizable in that relational forms of bullying were more typical experiences for female than male students at university, while males were more often engaged in physical forms of bullying than females (although these instances were rarely reported).

Contextual norms associated with the communication of feedback regarding individual performance are also likely to influence cross-cultural rates and forms of bullying experienced in the university setting. Various verbal forms of bullying were the most typical experiences of students in university. The most often reported form of bullying in all countries was unjustified criticism, belittling or humiliation related to studies (together with mocking of personal qualities in the USA). So it seems that during university studies the forms of bullying transform to the same kind of verbal bullying that is typical in work environments. The research on workplace bullying shows that unjustified criticism of work performance is among the most frequently reported forms of bullying experienced at work (e.g., Keashly and Harvey 2005; Pörhölä et al. 2006). During university years, students' increasing attention is likely to turn towards study success, as they understand that it is going to affect their ability to integrate into work contexts in the near future.

Potentially confounded with norms for communicating performance feedback in university contexts is the voluntary nature of higher education and the inherent goal of qualifying for a future profession, aspects that are speculated to impact occurrence rates and forms of bullying in different ways. It is understandable that students who have pursued a university education would pay more attention to their own and their peers' study success and outcomes than students do at mandatory school levels. This could increase competition between students in the university context, and affect their bullying behavior. Further, since the ability to criticize others' study performance requires intellectual capacity and an understanding of learning demands and outcomes that are less developed at a young age, the importance of study-related criticism may not have occurred as prominently of an issue during mandatory schooling. Also cyberbullying was rarely reported, giving support to the suggestion by Lund and Ross (2016), that bullying interventions at university should not focus primarily or exclusively on cyberbullying but rather on peer aggression, bullying and victimization in general. 


\section{Limitations}

Although a total of 8497 students from 47 universities, in four countries on three continents participated in this study, giving a wider cross-cultural basis than ever before to examine students' experiences of bullying during higher education, the study has its limitations. As is typical of most surveys, also in this study male students were underrepresented to some extent in all countries except for Argentina. Further, due to different higher education structures, the average age of the respondents varied from 21.7 years in Argentina to 25.5 years in Estonia. Hence, the results may reflect better the experiences of female than male students and of slightly different age groups in the countries compared.

Further, in order to encourage honest reporting by students, anonymous responding to similarly structured questions were asked in each country. However, the differences in data collection methods between countries, such as using paper-and-pencil versus online questionnaire to be completed in a facility of own choice versus university facilities, could have had some effect, for example, on response rates, the representativeness of the student population, as well as on which students chose to complete the survey. While the possible effects of these differences on the results remain unclear, the reliability of the results is examined in the following section by means of construct validity analysis.

\section{Contributions to construct validity}

A difficulty in advancing bullying research is associated with concerns of validity and arguments over definitions of the phenomenon. A key theoretical contribution the current study offers is to shed light on the transformation of school-based forms of bullying into forms that are more readily identified in work and organizational contexts. Shifting methodological focus from content validity to criterion-related validity places more emphasis on the operationalization of bullying via different forms of communication behavior that convey aggression in university contexts. The current study suggests aggressive behaviors used to bully others in school may morph into aggressive behaviors that continue to bully others in the workplace via more contextually normed communication strategies. The study design utilizes convergent validity to reinforce the pursuit of cross-cultural studies as a way to advance research investigating the developmental shift in the communication of bullying behaviors as they are adapted across time, contexts, and expressed in different cultures.

The predictive validity of the current study is demonstrated in comparing the findings with previous reports from studies that have included relatively similar definitions, measures, and response options. The generalizability of the results to the university student population was good in the small countries of Estonia and Finland. The community sample collected in the USA represented well the student populations in universities in which data were collected. And in Argentina, 
a relatively under-studied country with regard to bullying, a large convenience sample now sets a benchmark to advance new studies in that country.

For example, in the U.S. sample, the frequency of peer victimization at least occasionally (11.9\%) was somewhat higher, while the frequency of bullying perpetration (3.5\%) was only slightly lower than corresponding frequencies reported earlier by Marraccini et al. (2015; 9\% victims, 3.8\% perpetrators), and Chapell et al. (2004; 6.1\% victims, $5.1 \%$ perpetrators). Bullying by university personnel, at least occasionally, was also reported more often in this study $(8.9 \%)$ than in studies by Chapell et al. (4.7\%) and Marraccini et al. (4\%). So, students' experiences of bullying may differ to some extent between individual universities even across the same country.

Regarding Argentina, published studies of bullying at the university level were not available to support convergent validity, but trends do support predictive validity. For example, previous published studies on primary and secondary school showed a high level of peer bullying. More than half of primary school students in Argentina reported having been bullied by peers (Roman and Murillo 2011), with boys suffering more insults and threats, robberies and physical and verbal violence than girls. Still in secondary schools in Buenos Aires, $66.1 \%$ of students reported being bullied by peers, including experiences of mistreatment or humiliation, being mocked, being excluded from activities, and being told hurtful things (D’Angelo and Fernández 2011). Although the results indicate a high prevalence of bullying in the sample, participants reported the frequency of bullying experiences at the university decreased compared to pre-university studies, which is consistent with developmental trends in bullying occurrence rates cross-culturally.

Further, to reinforce convergent validity in this study, bullying experiences were assessed in two ways: by measuring overall (global) bullying victimization and perpetration, and by measuring exposure to different bullying forms. The large category of verbal bullying was divided into three subcategories to represent different messages in this type of bullying (face threat, personal qualities, and academic success). When data were collected, social awareness of bullying in primary and secondary school settings was quite high in Finland and the USA and increasing attention was paid to it in Estonia. Even though there was no clear term that refers to bullying in Spanish, the communication behaviors used to illustrate forms of bullying were recognizable by participants in Argentina. As can be expected, the two assessment methods evoked slightly different responses in Argentina, as students reported higher frequencies of overall victimization than different forms of victimization. Despite the definition given in the survey questionnaire, the lack of a common term might have brought different interpretations in the respondents' minds, and could explain the differences between the reports of victimization to overall bullying and to more detailed forms of bullying in Argentina. Future studies could benefit from including assessment of both the form and content for each type of bullying. 


\section{Practical implications}

While it is essential to increase awareness of the bullying that students experience during higher education, it is also necessary to develop anti-bullying policies and mechanisms for correcting outcomes for both students and personnel in universities. As the forms of bullying in university start to reflect those typical in the workplace, it is important to help students identify these forms in their own and others' behavior. In order to help students successfully complete their studies and to support their well-being and ethical professional development, students should be provided skills that are needed in the defense against bullying when they confront it in the university or later in the workplace.

In their literature review, Pörhölä et al. (2019) demonstrate the existence of studies to show that being bullied by peers is associated with academic problems and deficiencies in academic achievements in childhood and adolescence, however, they also argue this association may fall away as students grow up. Holt et al. (2014), for example, found that past bullying experiences were not associated with academic performance in college. Pörhölä et al. suggest that bullying victims at university could be individuals who are very focused on their studies and have high expectations for their study success, and therefore might be particularly sensitive to the feedback and critique they receive of their study performances. The findings of the present study emphasize the need to discuss with students the principles of giving and receiving encouraging and constructive feedback on study performances. As Keashly and Wajngurt (2016) argue, features of academe promote an environment in which ideas are subjected to rigorous scrutiny and critique, and, in such an environment, dissent and disagreement are valued and expressed through vibrant debate and dialogue. What is permitted and promoted in academic contexts may be viewed in other social contexts as inappropriate and even abusive behavior. Therefore, sharing an understanding of what is considered appropriate interaction and behavior in the academic context is critical.

Further, clinicians at student health services and counseling centers, staff in student affairs divisions and offices, and others who work with university students regarding their socioemotional well-being may benefit from systematically assessing students' bullying experiences at university to see to what extent bullying is an issue for the institution or a threat to an individual student. When examining bullying in higher education, it is important to include assessment of study-related forms of bullying. Also, student unions have an important role in increasing awareness of bullying and showing disapproval of such behaviors among students, which may help students to more safely transition from the university peer community to the workplace communities of their future.

Acknowledgements Open access funding provided by University of Eastern Finland (UEF) including Kuopio University Hospital.

Funding In Finland, the data collection for this research was supported by the Ministry of Social Affairs and Health, Ministry of Education and Culture, and Finnish Student Health Service. 


\section{Compliance with ethical standards}

Conflict of interest The authors declare that they have no conflict of interest.

Open Access This article is distributed under the terms of the Creative Commons Attribution 4.0 International License (http://creativecommons.org/licenses/by/4.0/), which permits unrestricted use, distribution, and reproduction in any medium, provided you give appropriate credit to the original author(s) and the source, provide a link to the Creative Commons license, and indicate if changes were made.

\section{References}

Ahmer, S., Yousafzai, A. W., Bhutto, N., Alam, S., Sarangzai, A. K., \& Iqbal, A. (2008). Bullying of medical students in Pakistan: A cross-sectional questionnaire survey. PLoS ONE, 3(12), e3889. https://doi.org/10.1371/journal.pone.0003889.

Beran, T. N., Rinaldi, C., Bickham, D. S., \& Rich, M. (2012). Evidence for the need to support adolescents dealing with harassment and cyber-harassment: Prevalence, progression, and impact. School Psychology International, 33, 562-576.

British Medical Association (BMA) (2006). Medical students' welfare survey report. Retrieved April 15, 2014 from http://www.bma.org/ap.nsf/content/WELFARE2006.

Chapell, M. S., Casey, D., De la Cruz, C., Ferrell, J., Forman, J., Lipkin, R., et al. (2004). Bullying in college by students and teachers. Adolescence, 39, 53-64.

Chapell, M. S., Hasselman, S. L., Kitchin, T., Lomon, S. N., MacIver, K. W., \& Sarullo, P. L. (2006). Bullying in elementary school, high school, and college. Adolescence, 41, 633-648.

Cooper, J. R. M., Walker, J., Askew, R., Robinson, J. C., \& McNair, M. (2011). Students' perceptions of bullying behaviours by nursing faculty. Issues in Educational Research, 21, 1-21.

Cowie, H., Bauman, S., Coyne, I., Myers, C.-A., Pörhölä, M., \& Almeida, A. (2013). Cyberbullying amongst university students. An emergent cause for concern? In P. K. Smith \& G. Steffgen (Eds.), Cyberbullying through the new media: Findings from an international network (pp. 165-177). London: Psychology Press.

Craig, W., Harel-Fisch, Y., Fogel-Grinvald, H., Dostaler, S., Hetland, J., Simons-Morton, B., et al. (2009). A cross-national profile of bullying and victimization among adolescents in 40 countries. International Journal of Public Health, 54, 216-224. https://doi.org/10.1007/s00038-009-5413-9.

Currie, C., Zanotti, C., Morgan, A., Currie, D., de Looze, M., Roberts, C., et al. (Eds.). (2012). Social determinants of health and well-being among young people. Health behaviour in school-aged children (HBSC) study: International report from the 2009/2010 survey (Health Policy for Children and Adolescents, No. 6). Copenhagen: WHO Regional Office for Europe.

Curtis, J., Bowen, I., \& Reid, A. (2007). You have no credibility: Nursing students' experiences of horizontal violence. Nurse Education in Practice, 7, 156-163.

D’Angelo, L.A., \& Fernández, D. R. (2011). Clima, conflictos y violencia en la escuela [climate, conflicts and school violence]. Buenos Aires, Argentina: United Nations Children's Fund (UNICEF) \& Latin American School of Social Sciences (FLACSO). Retrieved March 15, 2018 from https://www.unice f.org/argentina/spanish/clima_conflicto_violencia_escuelas.pdf.

Education at a glance 2017: OECD indicators. (2017). Retrieved 21.7.2019 from https://read.oecd-ilibr ary.org/education/education-at-a-glance-2017_eag-2017-en\#page222.

Espelage, D. L., Hong, J. S., \& Mebane, S. (2016). Recollections of childhood bullying and multiple forms of victimization: Correlates with psychological functioning among college students. Social Psychology of Education, 19(4), 715-728.

Finn, J. (2004). A survey of online harassment at a university campus. Journal of Interpersonal Violence, $19,468-483$.

Giovazolias, T., \& Malikiosi-Loizos, M. (2016). Bullying at Greek universities: An empirical study. In H. Cowie \& C.-A. Myers (Eds.), Bullying among university students: Cross-national perspectives (pp. 110-126). London: Routledge.

Gladden, R. M., Vivolo-Kantor, A. M., Hamburger, M. E., \& Lumpkin, C. D. (2014). Bullying surveillance among youths: Uniform definitions for public health and recommended data elements (version 
1.0.). Atlanta, GA: National Center for Injury Prevention and Control, Centers for Disease Control and Prevention and U.S. Department of Education.

Holt, M. K., Greif Green, J., Reid, G., DiMeo, A., Espelage, D. L., Felix, E. D., et al. (2014). Associations between past bullying experiences and psychosocial and academic functioning among college students. Journal of American College Health, 62(8), 552-560. https://doi.org/10.1080/07448 481.2014.947990.

Human development indices and indicators: 2018 statistical update. (2018). New York: United Nations Development Programme. Retrieved 20.7.2019 from http://hdr.undp.org/sites/default/files/2018_ human_development_statistical_update.pdf.

Keashly, L., \& Harvey, S. (2005). Emotional abuse in the workplace. In S. Fox \& P. E. Spector (Eds.), Counterproductive work behavior: Investigations of actors and targets (pp. 201-235). Washington, DC: American Psychological Association.

Keashly, L., \& Wajngurt, C. (2016). Faculty bullying in higher education. Psychology and Education, 53, 79-90.

Kraft, E., \& Wang, J. (2010). An exploratory study of the cyberbullying and cyberstalking experiences and factors related to victimization of students at a public liberal arts college. International Journal of Technoethics (IJT), 1, 74-91.

Kunttu, K., \& Pesonen, T. (2013). Student health survey 2012: A national survey among Finnish university students (Research publications, 47). Helsinki, Finland: Finnish Student Health Service. Retrieved 12.3.2015 from http://www.yths.fi/filebank/2263-KOTT2012_in_English.pdf.

Kunttu, K., Pesonen, T., \& Saari, J. (2017). Student health survey 2016: A national survey among Finnish university students (Research publications, 48). Helsinki, Finland: Finnish Student Health Service. Retrieved 8.3.2018 from http://www.yths.fi/filebank/4310-KOTT_englanti_2016.pdf.

Lavikainen, E. (2010). Opiskelijan ammattikorkeakoulu 2010. Tutkimus ammattikorkeakouluopiskelijoiden koulutuspoluista, koulutuksen laadusta ja opiskelukyvystä [Student's university of applied sciences 2010. Research on the study tracks, views on the quality of education, and own ability to study of students in the universities of applied sciences]. Helsinki, Finland: Opiskelijajärjestöjen tutkimussäätiö Otus.

Lund, E. M., \& Ross, S. W. (2016). Bullying perpetration, victimization, and demographic differences in college students: A review of the literature. Trauma, Violence, \& Abuse, 18, 348-360. https://doi. org/10.1177/1524838015620818.

Marraccini, M. E., Weyandt, L. L., \& Rossi, J. S. (2015). College students' perceptions of professor/ instructor bullying: Questionnaire development and psychometric properties. Journal of American College Health, 63, 563-572. https://doi.org/10.1080/07448481.2015.1060596.

Matsunaga, M. (2010). Individual dispositions and interpersonal concerns underlying bullied victims' self-disclosure in Japan and the US. Journal of Social \& Personal Relationships, 27, 1124-1148. https://doi.org/10.1177/0265407510380084.

Nansel, T. R., Overpeck, M., Pilla, R. S., Ruan, W. J., Simons-Morton, B. G., \& Scheidt, P. (2001). Bullying behaviors among U.S. youth: Prevalence and association with psychosocial adjustment. Journal of the American Medical Association, 285, 2094-2100.

National Union of Students (NUS) (2008). Student Experience Report. Retrieved March 6, 2014 from http://www.nus.org.uk/PageFiles/4017/US_StudentExperienceReport.pdf.

Noel, G., Miguez, D., Gallo, P., Bianchi, M., Lionetti, L., Pomes, A. L., et al. (2009). Violencia en las escuelas desde una perspectiva cualitativa [Violence in schools from a qualitative perspective]. Buenos Aires: Ministerio de Educación de la Nación.

Olweus, D. (1993). Bullying at school: What do we know and what can we do. Oxford: Blackwell.

Pontzer, D. (2010). A theoretical test of bullying behavior: Parenting, personality, and the bully/victim relationship. Journal of Family Violence, 25, 259-273. https://doi.org/10.1007/s10896-009-9289-5.

Pörhölä, M. (2017). Kiusaaminen opiskelijoiden keskuudessa [Bullying among students]. In K. Kunttu, A. Komulainen, K. Makkonen, \& P. Pynnönen, (Eds.), Opiskeluterveys (online version). Helsinki, Finland: Duodecim. Retrieved 18.4.2018 from http://www.oppiportti.fi/op/ote00012/do (Available with user name).

Pörhölä, M., Almonkari, M., \& Kunttu, K. (2019). Bullying and social anxiety experiences in university learning situations. Social Psychology of Education. https://doi.org/10.1007/s11218-019-09496-4.

Pörhölä, M., Karhunen, S., \& Rainivaara, S. (2006). Bullying at school and in the workplace: A challenge for communication research. In C. S. Beck (Ed.), Communication Yearbook 30 (pp. 249-301). Mahwah, NJ: Erlbaum. 
Roman, M., \& Murillo, F. J. (2011). America Latina: Violencia entre estudiantes y desempeño escolar [Latin America: Violence among students and their academic performance]. Revista Cecopal, 104, 37-54.

Rospenda, K. M., Richman, J. A., Wolff, J. M., \& Burke, L. A. (2013). Bullying victimization among college students: Negative consequences for alcohol use. Journal of Addictive Diseases, 32, 325-342. https://doi.org/10.1080/10550887.2013.849971.

Schenk, A. M., \& Fremouw, W. J. (2012). Prevalence, psychological impact, and coping of cyberbully victims among college students. Journal of School Violence, 11, 21-37.

Seals, D., \& Young, J. (2003). Bullying and victimization: Prevalence and relationship to gender, grade level, ethnicity, self-esteem, and depression. Adolescence, 38, 735-747.

Sinkkonen, H. M., Puhakka, H., \& Meriläinen, M. (2014). Bullying at a university: Students' experiences of bullying. Studies in Higher Education, 39, 153-165. https://doi.org/10.1080/03075 079.2011.649726.

Volk, A. A., Dane, A. V., \& Marini, Z. A. (2014). What is bullying? A theoretical redefinition. Developmental Review, 34, 327-343.

Wensley, K., \& Campbell, M. A. (2012). Heterosexual and nonheterosexual young university students' involvement in traditional and cyber forms of bullying. Cyberpsychology, Behavior \& Social Networking, 15, 649-654. https://doi.org/10.1089/cyber.2012.0132.

Young-Jones, A., Fursa, S., Byrket, J. S., \& Sly, J. S. (2015). Bullying affects more than feelings: The long-term implications of victimization on academic motivation in higher education. Social Psychology of Education, 18, 185-200. https://doi.org/10.1007/s11218-014-9287-1.

Publisher's Note Springer Nature remains neutral with regard to jurisdictional claims in published maps and institutional affiliations.

Maili Pörhölä is an adjunct professor in the School of Humanities at the University of Eastern Finland. Her career has focused on communication research investigating bullying and abuse in social relationships, with a special interest in the transference of these experiences from primary, secondary and higher education contexts to the workplace, examining impacts on individual psychosocial well-being.

Kristen Cvancara is a professor in the Department of Communication Studies at Minnesota State University, Mankato, USA. Her areas of expertise include interpersonal communication and social influence. She specializes in the study of verbal aggression, investigating how it is learned and used in romantic, familial, and friendship relationships.

Esta Kaal is a lecturer and researcher at Baltic Film, Media, Arts and Communication School, Tallinn University, Estonia. She works in the communication research field investigating organizations in public, business, and university contexts. Her main research interests include environmental, health and risk communication.

Kristina Kunttu adjunct professor, is a senior researcher in the Finnish Student Health Service (FSHS) and has been the principal investigator in the University Student Health surveys. She is also a general practitioner in FSHS. In her research she focuses on issues of university student well-being.

Kaja Tampere Tartu Health Care College, Estonia, researches social and health communication processes, specifically topics involving bullying and associated behaviors.

Maria Beatriz Torres is currently tenured associate professor and chair of Public Health at Mercyhurst University in Erie, Pennsylvania. Her research focuses on bullying, health disparities, community health promotion, entertainment education and community based participatory action research. 


\section{Affiliations}

\section{Maili Pörhölä ${ }^{1}$ (D) Kristen Cvancara ${ }^{2}$ (D) Esta Kaal ${ }^{3}$ (D) Kristina Kunttu $^{4}$ (D) Kaja Tampere ${ }^{5}$ (D) Maria Beatriz Torres ${ }^{6}$ (D)}

Kristen Cvancara

kristen.cvancara@mnsu.edu

Esta Kaal

esta.kaal@tlu.ee

Kristina Kunttu

kristina.kunttu@historia-memoria.fi

Kaja Tampere

kaja.tampere@gmail.com

Maria Beatriz Torres

mabeatorres@gmail.com

1 University of Eastern Finland, Joensuu, Finland

2 Minnesota State University Mankato, Mankato, USA

3 Tallinn University, Tallinn, Estonia

4 Finnish Student Health Service, Helsinki, Finland

5 Tartu Health Care College, Tartu, Estonia

6 Mercyhurst University, Erie, USA 